\title{
DESARROLLO INDUSTRIAL, ESTRATEGIA REPRESIVA Y CONFLICTIVIDAD SOCIAL EN EL NORESTE DE CHUBUT: EL “OPERATIVO VIGILANTE" Y EL TRELEWAZO DE 1972 EN PERSPECTIVA HISTÓRICA
}

\section{INDUSTRIAL DEVELOPMENT, REPRESSIVE STRATEGY AND SOCIAL CONFLICTIVITY IN THE NORTHEAST OF CHUBUT: THE "SECURITY OPERATION" AND THE TRELEWAZO OF 1972 IN HISTORICAL PERSPECTIVE}

\author{
AXEL BINDER (INSHIS / UNP) \\ Instituto de Investigaciones Históricas \\ Universidad Nacional de la Patagonia \\ axelbind@gmail.com
}

\section{Resumen:}

En este artículo abordaremos el fenómeno de masas del Trelewazo de octubre de 1972, entendiéndolo como una expresión regional del proceso de lucha de clases del periodo, y en particular, como el resultado combinado tanto del acelerado proceso de industrialización como de la incorporación de la región al circuito represivo general. Ambos procesos dieron lugar a nuevas relaciones sociales, estimulando una creciente politización cuya "gimnasia" deliberativa y organizativa (en asambleas y comisiones) resulta fundamental para comprender de manera más íntegra las dinámicas de la pueblada. El "Operativo Vigilante" que dio lugar al Trelewazo, propició el alineamiento de las fuerzas políticas que se oponían al régimen, entorno a una demanda central que los supo articular: la libertad de los presos políticos y la defensa de los derechos humanos.

\section{Palabras clave:}

Polo de desarrollo - Polo represivo - comisiones - Operativo Vigilante - Trelewazo

\begin{abstract}
:
This article approaches the mass protest of Trelewazo in October 1972, understood it as a regional expression of the class struggle process of the period, and in particular, as the combined result of both the accelerated industrialization process and the incorporation of the region into the general repressive circuit. Both processes gave rise to new social relations, stimulating a growing politicization whose deliberative and organizational "gymnastics" (in assemblies and commissions) is essential to understand the dynamics of the protest. The "Vigilant Operation" led to the alignment of the political forces that opposed the regime, around a central demand articulated them: the freedom of political prisoners and the defense of human rights.
\end{abstract}

\section{Keywords:}

Development pole - repressive pole - commissions - Vigilant Operation - Trelewazo 


\section{DESARROLLO INDUSTRIAL, ESTRATEGIA REPRESIVA Y CONFLICTIVIDAD SOCIAL EN EL NORESTE DE CHUBUT: EL “OPERATIVO VIGILANTE" Y EL TRELEWAZO DE 1972 EN PERSPECTIVA HISTÓRICA}

AXEL BINDER (INSHIS / UNP)

axelbind@gmail.com

\section{Seguridad y Desarrollo: dos caras de una misma estrategia de dominación.}

Las medidas de promoción industrial para el Noreste de Chubut ${ }^{1}$, se enmarcan en la política de Polos de Desarrollo que impulsa la "Revolución Argentina" desde mediados de 1969 (Schvarzer, 1987; Gatica, 2010; Cifuentes, 2015, Ibarra y Hernández, 2016; Pérez Álvarez, 2016). La industrialización que promueve la dictadura de Onganía, tiene un destacado contenido geopolítico y de control social que responde tanto a su crisis orgánica de dominación como al auge de los proyectos revolucionarios y a la profundización de un ciclo de rebelión que tendrá en el Cordobazo uno de sus hitos más sobresalientes.

A ese proceso de industrialización subsidiada, lo denominaremos "desarrollismo en clave de seguridad nacional", para destacar el estratégico sentido de dominación y de control social que subyace a la política económica. Si bien las FFAA siempre consideraron a la Patagonia como una región vacía de gente y cargada de recursos estratégicos -y su defensa un objetivo militar primordial para el interés y desarrollo de la Nación-, hacia mediados de la década del '60 esa combinación entre Seguridad (represión) y Desarrollo (acumulación) comienza a adoptar connotaciones y articulaciones específicas.

La ley de Defensa Nacional 16.970 que decreta Onganía en octubre de 1966, constituye el núcleo de una nueva estructuración del Estado y de un sistema represivo, del tipo contrainsurgente. ${ }^{2}$ En su artículo $1^{\circ}$ establecía "las bases jurídicas orgánicas y funcionales fundamentales para la preparación y ejecución de la Defensa Nacional, con el fin de lograr y mantener la Seguridad Nacional necesaria para el desarrollo de las actividades del país, en procura de sus objetivos nacionales". ${ }^{3}$ El vago objetivo de esa "Seguridad Nacional" era procurar que "los intereses vitales de la Nación se ballen a cubierto de interferencias y perturbaciones sustanciales". El Consejo Nacional de Seguridad (CONASE) era uno de esos órganos para tal fin; entre sus competencias, la ley 16.970 fijaba que el CONASE podría a su vez crear los organismos que considerase necesarios,

\footnotetext{
${ }^{1}$ La región NE de Chubut, comprende los departamentos de Rawson (las ciudades de Rawson y Trelew) y Biedma (Puerto Madryn y Península Valdés).

2 Ruy Mauro Marini, ha sostenido que la característica que define a un Estado de tipo contrainsurgente o contrarrevolucionario, es que en su estructuración vertical -propia de las FFAA- pueden identificarse dos ramas: la militar (el Estado Mayor Conjunto) y la económica, "representada por los ministerios económicos, así como las empresas estatales de crédito, producción y servicios, cuyos puestos clave se encuentran ocupados por tecnócratas civiles y militares" (Marini, 1978). Marini sostiene que el órgano supremo es el Consejo de Seguridad Nacional, "en el que se entrelazan los representantes de la rama militar con los delegados directos del capital; y los órganos del servicio de inteligencia, que informan, orientan y preparan el proceso de toma de decisiones (...) Así, el Consejo de Seguridad Nacional es el ámbito donde confluyen ambas ramas, entrelazándose, y se constituye en la cúspide, el órgano clave del Estado de contrainsurgencia" (Marini, 1978).

${ }^{3}$ Ley de Defensa Nacional 16.970, publicado en Colección de Debates Parlamentarios de la Defensa Nacional: Antecedentes legales y parlamentarios 1944-1986, Ministerio de Defensa, 2010.
} 
establecer normas legales, zonas de seguridad, fijar estrategias y coordinar su acción con el CONADE (Consejo Nacional de Desarrollo) "a fin de armonizar los planes respectivos".

CONASE y CONADE encarnan institucionalmente la necesidad del régimen de “ordenar" la sociedad y "normalizar" la economía, acorde a las exigencias del patrón de acumulación bajo hegemonía del capital monopólico extranjero. ${ }^{5}$ Reflejan la decisión política de institucionalizar la relación entre seguridad y desarrollo. Simbólicamente fuerte, y abonando a la idea de que el corazón del estado contrainsurgente son los organismos de seguridad nacional (Marini, 1978), el CONASE se instaló en el edificio del Congreso Nacional, ejerciendo también un rol "legislativo":

"Antes de su promulgación, todas las leyes son enviadas a CONADE para que se determinen sus efectos sobre el desarrollo económico y a CONASE para un examen de sus efectos sobre la seguridad nacional. Cada consejo tiene el poder de 'veto-suspensivo', puesto que las leyes consideradas en detrimento del desarrollo y/o de la seguridad son devueltas a los ministros responsables para' su revisión". (Snow, 1972: 73).

En el contexto de la guerra fría y de la asimilación de la Doctrina de Seguridad Nacional (DSN), el "desarrollo" era pensado por estos sectores militares como prerrequisito de "seguridad" y reaseguro del orden (y viceversa). Osiris Villegas, secretario CONASE desde 1968 sostenía que "no puede haber seguridad sin desarrollo, como tampoco desarrollo sin seguridad". ${ }^{6}$ En su libro "Políticas y estrategias para el desarrollo y la seguridad nacional", explicaba que

"Los conceptos sobre Desarrollo, Seguridad y Defensa Nacional están íntimamente ligados, son interdependientes e interrelacionados entre sí, como los intereses y valores deseados, la capacidad de contener presiones opuestas a su logro y la aptitud para rechazar agresiones. Constituyen así una verdadera trilogía, partes de una unidad, de un todo, que es la política nacional, una unidad dentro de la cual se apoya y complementan mutuamente y en donde la falta o ausencia de uno de ellos, prácticamente neutraliza a los otros." (Villegas, 1969: 80)

Esto suponía que el control inmediato de la protesta social (competencia de la "seguridad") permitiría una mejor aplicación de las medidas desarrollistas; éstas a su vez, propiciarían un despegue económico que ayudaría a enfriar la conflictividad entendida como amenaza a la "Seguridad Nacional". Belén Zapata sostiene que el programa de la FFAA se proponía integrar "espacios vacíos", reparar la desigual distribución de la población, el deficitario desarrollo infraestructural en ciertas zonas y otorgar prioridad a la explotación de algunas industrias consideradas prioritarias (Zapata, 2014: 40).

La estrategia de acumulación y la estrategia represiva son complementarias, representando dos caras de una misma estrategia de dominación, que buscaba soslayar la crisis orgánica (de hegemonía). Al hablar de industrialización en clave de seguridad nacional, buscamos enfatizar esa particular articulación del binomio seguridad-desarrollo que se ensaya en Patagonia, donde el despliegue industrial se combina con la estrategia represiva y los dispositivos de "seguridad" que monta la dictadura. La idea de los polos de desarrollo (planificación a cargo de CONASE y CONADE) cuya puesta en marcha por el gobierno nacional se acelera luego del "Cordobazo",

\footnotetext{
${ }^{4}$ Ley de Defensa Nacional 16.970, art.13, op. cit.

5 Sostiene Eduardo Basualdo al respecto que “...el aparato estatal se adecuó a las necesidades del proceso de acumulación de las fracciones de capital dominantes (...) El estado fue uno de los sustentos fundamentales para el fortalecimiento de las empresas oligopólicas industriales a través de múltiples mecanismos redistributivos (sobreprecios en las compras estatales, líneas de crédito a tasas de interés negativa, regímenes de promoción industrial, subvaluación de insumos industriales producidos por las empresas del estado, excepciones arancelarias para insumos, etc." (Estudios de Historia Económica Argentina, Buenos Aires, Ed. S XXI, 2010, pp.76-77)

${ }^{6}$ Osiris Villegas, Guillermo, "Seguridad, Política, Estrategia", Temas Militares I: 4, febrero 1968, p. 5, citado en Snow, Peter (1972).
} 
debe ser leída como la respuesta de la clase dominante a un marco de rebelión social y de ofensiva de la clase obrera. A partir de ese momento el régimen militar acrecienta cada vez más su perfil contrarrevolucionario y represivo, haciendo eje discursivamente en la "Seguridad Nacional".

Inmediatamente después del Cordobazo, Onganía removió a todo su gabinete ministerial (entre ellos la cuestionada figura de Krieger Vasena, asociada a los trust y monopolios extranjeros) y anunció la llegada del "Tiempo Social", esperando con estas medidas "gatopardistas" recuperar cierto margen de gobernabilidad. En ese marco se da impulso a la promoción patagónica, cuyas políticas transformarían especialmente la estructura económico-social del NE de Chubut. Estas medidas de industrialización constituyen a su vez medidas de "seguridad", en tanto que tienen principalmente por objeto descentralizar las regiones conflictivas del país (que son las de mayor desarrollo fabril e industrial), desarrollando regiones económicamente "postergadas" y estimulando la relocalización tanto de capitales industriales como de mano de obra (Varesi, 2013).

En primer término, ello se expresa con la puesta en marcha del proyecto de COPEDESMEL ${ }^{7}$ para la producción de aluminio, anunciada el 10 de julio de 1969. Este proyecto -sostenía Onganía- implicaría "la creación de un polo de desarrollo patagónico" que traería aparejado "la radicación estable de habitantes en la provincia del Chubut, con todas las repercusiones que ello representa para la economía de la zona" (Diario Jornada, 12/7/69). Seis meses más tarde promulgaría el decreto 18.447/69 de "Promoción Industrial de la Patagonia" (que eximía a las empresas del impuesto a las ventas por otros 10 años más); y al mes siguiente del anuncio del nuevo régimen, el interventor de la Provincia (Contralmirante Pérez Pittón) hacía colocación de la piedra fundamental (Diario Jornada, 11/12/1969) del Parque Industrial de Trelew (PIT) donde se concentraría la actividad textil. El ministro de Economía de la provincia de Chubut sostuvo en ese acto que

“Todos los hombres y mujeres de cualquier lugar de la provincia deben comprender que la instalación de una planta de aluminio en Puerto Madryn, la implantación de un centro textil en Trelew, la reactivación pesquera en el puerto de Rawson, el desarrollo de un polo metalúrgico y mecánico en Comodoro Rivadavia o la creación de un centro turístico en Esquel, benefician individual y colectivamente a la comunidad entera del Chubut" (Diario Jornada, 11/12/1969, tapa).

Al mismo tiempo que se anuncian estas medidas para el desarrollo regional, comienzan a ser trasladados al penal U6 de Rawson los presos políticos del Cordobazo, incorporándose la región al circuito represivo en calidad de "Siberia Argentina", y generando inmediatas reacciones políticas de solidaridad. Así en el NE de Chubut, a la conformación de un polo de desarrollo industrial se le habría de ir superponiendo, a su vez, la constitución de un polo represivo (Bahía Blanca/Base Puerto Belgrano - Trelew/Base Zar - Rawson/U6) a cargo de la Armada Argentina, que tendría su bautismo de terror el 22 de agosto de $1972 .{ }^{8}$ Se irán combinando así

\footnotetext{
${ }^{7}$ La Comisión Permanente de Planeamiento del Desarrollo de los Metales Livianos, fue el organismo dependiente de la Fuerza Aérea que tuvo a su cargo el proyecto de la planta de aluminio, explotando el puerto de aguas profundas en Madryn, y construyendo una usina hidroeléctrica en Futaleufú que proveería energía a bajo costo, permitiendo la competitividad de la producción de aluminio en Puerto Madryn.

${ }^{8}$ La Masacre de Trelew fue el fusilamiento en la Base Zar de 19 militantes revolucionarios que se habían fugado del penal de Rawson una semana antes, el día 15 de agosto. En esa madrugada del 22 de agosto, "cerca de las 3.30, fueron despertados con patadas en las puertas y gritos. Sosa, Bravo, Del Real, Herrera, Marandino y Marchant los obligaron a salir de las celdas y a formar dos filas en el pasillo, con la cabeza hacia el piso, para luego abrir fuego sobre los diecinueve, descargando por completo sus ametralladoras. Cuando finalizaron las ráfagas, quienes todavía se encontraban vivos fueron rematados con tiros de gracia. A pesar de ello, lograron sobrevivir seis de los presos María Antonia Berger, Ricardo Haidar, Alberto Camps, Miguel Ángel Polti, Alfredo Kohon y Rubén Bonet-, quienes luego de estar mucho tiempo en el piso de sus celdas desangrándose y sin recibir ningún tipo de atención médica, fueron llevados en camillas hacia la enfermería, donde se los dejó varias horas más sin atenderlos, esperando que
} 
políticas de desarrollo (promoción industrial) con medidas de "seguridad", dinamizando procesos que reconfigurarían el espacio regional y que impactarían profundamente en las relaciones sociales que se tejen al interior de ese territorio.

Aquí se anida la especificidad regional que imprime características locales a una conflictividad social de raíz "nacional". De aquí se desprenden dos factores sin los que difícilmente puede pensarse el Trelewazo: 1) como resultado del proceso acelerado de industrialización, una fuerte corriente migratoria de mano de obra que genera una urbanización espontánea y precaria; 2) como resultado de la incorporación de la región al circuito represivo general, se consolidan prácticas y redes de solidaridad política en torno a los dispositivos represivos en la región. Ambos factores impulsan procesos de politización dando lugar a las "Comisiones Barriales" y a las "Comisiones de Solidaridad".

\section{Migración interna, urbanización espontánea y Comisiones Barriales}

En el Trelewazo, se expresa materialmente una fuerza social opositora que revierte la relación de fuerzas en favor del campo popular (siendo la "pueblada" el observable empírico). En ella, ocupa un lugar central la clase obrera migrante; los nuevos trabajadores que llegan al polo industrial se erigen como una de las principales fuerzas políticas, (junto a los estudiantes) que logran movilizar miles de cuerpos que habitan las barriadas populares, en las márgenes de la ciudad. Por eso sostenemos que sin el estudio de las transformaciones de la estructura económica regional, no se llega a dimensionar la conformación de ese grupo social y la impronta que su praxis política tuvo en nuestra historia regional y en Trelewazo. Sin su presencia y movilización, no se hubiese constituido una fuerza social (integrada por sectores de la clase obrera y la pequeña burguesía) capaz de revertir la relación de fuerzas con el régimen militar para imponer sus demandas.

El boom demográfico que se registra desde fines de los ' 60 , corre en paralelo con el despoblamiento del interior de la provincia; Cristian Hermosilla sostiene que

"Es factible decir que entre 1947 y 1991 parte de la población rural dispersa haya migrado hacia otras regiones, siendo el momento más álgido entre la década del 70 y el 80 , en coincidencia con la promoción industrial que terminó convirtiendo a algunas ciudades de la provincia en verdaderos polos de atracción.” (Hermosilla Rivera, 2013: 63)

Las políticas de Polos de Desarrollo transformaron la estructura económico- social de la región, alterando su dimensión material y afectando la dinámica de sus relaciones sociales (Pérez Álvarez, 2016). La población en el NE de Chubut (departamentos de Biedma y Rawson) se duplicó respecto del número registrado en 1960, pasando de 23mil a 41mil habitantes en 1970. Desde 1960, Trelew se había posicionado después de Comodoro Rivadavia, como la segunda ciudad más poblada de la provincia. Un censo a fines de 1968 realizado por el IDES (Instituto de Estudios Superiores), arrojaba para Trelew una población de 18.252 habitantes (Diario Jornada, 23/11/1968), mientras que en 1970 se censarían unos 24.214 habitantes y 6870 viviendas. ${ }^{9}$ La tasa de crecimiento anual de la población durante la década 60-70 fue del 12\%, y entre 1970 y 1972 ascendería al 20\% (Diario Jornada, 20/10/1972), momento que coincide con el "boom" del empleo textil.

El dinamismo que imprimieron las medidas de promoción industrial, trajo aparejado una corriente migratoria de mano de obra textil en Trelew que pasará de emplear 704 personas en 1970, a ocupar unas 2.473 hacia 1974, creciendo en un 213\% (Gatica, 2010: 147). Las medidas de

murieran. Finalmente, fallecieron Kohon y Polti durante el transcurso de la mañana, y Rubén Bonet en horas del mediodía, fusilado de un tiro en la cabeza." [Binder et al, Diario del Juicio. La masacre de Trelew 40 años después, Rawson, Secretaría de Cultura de la provincia de Chubut, 2015, p. 34]

${ }^{9}$ Censo Nacional de Población, Familias y Viviendas de 1970. 
promoción industrial para la región posteriores al Cordobazo, motorizaron un crecimiento geométrico de la población, tal como era de esperarse para una industrialización que proyectaba hacer uso extensivo de mano de obra. Según estimaciones de Irusta y Rodríguez (1993), la evolución de la población de Trelew fue de 27.000 personas en $1971 ; 30.000=1972 ; 34.000=1973$ y $38.000=1974$.

No obstante, este proceso no estuvo acompañado de una debida planificación que solventase la demanda habitacional en aumento, profundizando la marginalidad y los problemas sociales que se derivan de unas pésimas condiciones de vida. El boom demográfico (impulsado por la apertura de puestos de trabajo en la industria textil y metalúrgica) desató un déficit habitacional, que dio lugar a las tomas de tierras (Hermosilla, et al 2016) y a un acelerado proceso de urbanización. ${ }^{10}$ En el barrio "Norte", se censaron tan sólo 71 viviendas precarias; al año siguiente en 1972, se registrarían unas 625; mientras que el Barrio "La Laguna", donde habitaban unas 600 familias, se registraron unas 200 viviendas de tipo precario, y algunas de calidad constructiva media (Caracotche e Ibarra, 1973: 40). En total las estimaciones oficiales calculaban que para ese momento en Trelew,

"más de once mil personas (casi el $40 \%$ de la población total) habitaban en unas dos mil viviendas precarias, construidas por ellos mismos en tierras baldías, en sitios que carecían de urbanización previa y de servicios básicos. Solo el 20\% contaba con acceso al agua corriente y la energía eléctrica" (Fernández Picolo, 2014: 139-140. Subrayado nuestro)

Fueron surgiendo así de manera casi espontánea, nuevos asentamientos obreros en la periferia de la ciudad (hacia el noreste, en las proximidades del Parque Industrial), donde la carencia de infraestructuras y de servicios básicos (agua, cloaca, gas, escuelas, etc.) sometía a sus habitantes a unas paupérrimas y denigrantes condiciones de vida. ${ }^{11}$ Haciendo un balance de todo este proceso, Ibarra concluye que

"Por las características apuntadas, esta urbanización explosiva ha sido no planificada e improvisada desde el punto de vista urbanístico, irracional desde el punto de vista socioeconómico, y vejatoria desde el punto de vista humano. Ha significado la constitución de monstruos urbanos fuera de control que seguirán creciendo en condiciones opresivas para la mayoría de sus habitantes en tanto las elites se refugian en sus ghettos de privilegio." (Ibarra y Hernández, 2016: 103)

Se irían acumulando así una serie de derechos negados y de demandas insatisfechas (tanto materiales como de inclusión social y participación política) que no tardarían en gestar una articulación política, en torno a asociaciones barriales. Estas comisiones que surgen en el seno del barrio estimularon una "politización" en torno a estas luchas, cuya "gimnasia (deliberativa y organizativa, en asambleas y comisiones) resulta fundamental para comprender de manera más íntegra las dinámicas del Trelewazo de 1972.

Fueron los problemas en torno a la posesión de las tierras y al aprovisionamiento de agua potable, los que en principio estructuraron las luchas de las comisiones barriales, ganando de a poco espacio en los medios de comunicación y planteando el debate en la sociedad. ${ }^{2}$ En paralelo,

\footnotetext{
10 "Durante los últimos años se han multiplicado en Trelew los asentamientos humanos de este tipo, en los que el carácter precario de muchas viviendas debe sumarse la falta de servicios públicos indispensables y la situación de inestabilidad y marginamiento social" (Caracotche e Ibarra, 1973: 13)

${ }^{11}$ Muchos vivían en "casitas 'liliputienses' muy precarias, algunas de adobe; ya sin lugar donde construir las familias usaron como vivienda los vagones abandonados del trencito patagónico en el interior del galpón del ferrocarril (...) Obtenían el agua de las canillas de la estación del tren, a varias cuadras de sus casas y la juntaban en todos los recipientes que podían”. [Barberena, Daniel, Los barrios populares de Trelew en la década del '70, Trelew: Ed. TER, 2009, p. 12]

12 "Expusieron problemas Vecinos de un Barrio. Organizadores de la reunión decidieron invitar a representantes municipales a efectos de encontrar el asesoramiento imprescindible para iniciar acciones (...) quienes sugirieron en
} 
fueron aumentando también los reclamos de acceso a los servicios educativos y de salud, así como también la demanda de políticas de ayuda social al municipio y la provincia. Sin embargo explica Fernández Picolo-

"la lucha más significativa fue la que se llevó adelante para alejar la amenaza del desalojo, obtener la legitimación de la tenencia de las tierras ocupadas y alcanzar el reconocimiento al derecho adquirido por las 'mejoras' materiales realizadas. En este proceso tuvo lugar la constitución de comisiones barriales -incluso, en Rawson, llegó a formarse una comisión 'Inter-barrial'- y la intensificación de la disputa política." (Fernández Picolo, 2014: 140).

Analizando el rol de la Juventud Peronista en Rawson, su militancia y su inserción barrial, Jessica Murphy da cuenta de numerosas comisiones vecinales que para la misma época, reclaman también por agua potable (Barrio Perito Moreno) y los servicios públicos (Barrio Ribera y Belgrano), encontrando un núcleo fuerte de politización "surgido al calor de las necesidades de infraestructura y demandas barriales" (2017: 37).

Es así como en pleno proceso de expansión territorial de la ciudad (1969-1972), se consolidan las primeras formas de organización política en los barrios populares. Surgidas por iniciativa y necesidad de sus propios habitantes, estas comisiones autónomas representaban los intereses del barrio y su lucha por integrarse, a una ciudad en franca expansión que les daba la espada. La acuciante situación socioeconómica de sus habitantes, y la insalubridad de sus condiciones de vida, no tardarían en ganar espacio en el debate público y comenzar a ejercer presión política:

"La zona Barrio Norte-La Loma constituye en la actualidad uno de los conglomerados más importantes, por su extensión y población, y sin embargo continúa padeciendo, por una parte, la deficiente prestación de servicios esenciales, y por otra, una situación de notorio marginamiento físico y social. Se impone una fuerte promoción del sector, que procure su rehabilitación e integración al resto de la ciudad" (Caracotche e Ibarra, 1973: 14)

Hacia mediados de 1972, toma injerencia en el asunto el ministro provincial de Bienestar Social, y el Estado comienza a desarrollar incipientes planes de apoyo, sin abandonar los planes paralelos para erradicar esas "villas miseria". En agosto de 1972, el estado provincial avanza en la expropiación de las tierras de Melecio González, donde se emplazaba el populoso barrio "norte". Mediando institucionalmente a través de las comisiones de vecinos, se obtiene así en el barrio La Laguna un rudimentario suministro de agua potable, materiales y maquinarias para la mejora de viviendas, ropas, frazadas, colchones, y hasta elementos de cocina (donados por la esposa del interventor provincial). Esto generó cruces entre el municipio y el poder provincial. Relata Barberena que el ministro de bienestar Nores Martínez se dirigió

"a la municipalidad y en un duro cuestionamiento a las autoridades municipales les reclamó la insensibilidad ante las condiciones de vida de la población. El debate le costó la renuncia al intendente, quien recibió el apoyo de la organización de comerciantes” (2009:14).

En paralelo a la injerencia gubernamental en la problemática territorial de la clase obrera, entre 1968 y 1972 se acrecienta y consolida también la inserción en los barrios de las organizaciones políticas de base: primero del PC (Partido Comunista) y de la izquierda peronista (Juventud Peronista $^{13}$ y Frente de Izquierda Popular) y desde 1973 del marxismo (Frente Antiimperialista al

principio la formación de una comisión vecinal receptora de los problemas del barrio y a la vez canal de soluciones adecuadas en estrecha colaboración con las autoridades comunales (...) El barrio Gesi está constituido por un grupo de humildes construcciones edificadas en un sector de la ciudad poco favorecido por las características de la tierra y ciertamente desprovisto del buen amparo que ofrecen los servicios públicos. Entre las necesidades inmediatas los vecinos solicitaron el enripiado de algunas de las calles del barrio, por cuanto en las actuales condiciones y entre otros inconvenientes se limitan las posibilidades de provisión de agua potable..." (Diario Jornada, 1/07/1970).

13 "Durante una reunión realizada el 4 de mayo en la unidad básica '22 de agosto' del barrio La Laguna y con la presencia de numerosos vecinos, quedó constituida la comisión de ese barrio" (Diario Jornada, 7/5/1973, p.5). La 
Socialismo). El órgano de prensa del FIP, da cuenta para octubre de 1972, de disputas territoriales con la JP, tanto en Trelew como en Comodoro:

"En esos momentos apareció un auto con un altavoz ocupado por varios miembros (según dijeron) de la Juventud Peronista. Venían del centro, como es lógico. El altavoz comenzó a propalar consignas del Partido Justicialista mientras que el auto se esforzaba por colocarse a la cabeza de la columna. El hecho causó visible desagrado entre los manifestantes, algunos de los cuales recogieron piedras de las calles (no son asfaltadas) y comenzaron a ensayar su puntería contra las ventanillas del rodado (...) posteriormente llegaron al local de la Junta Popular "Albino Argüello' del Barrio San Martín varias personas que se identificaron como miembros de la Juventud Peronista y ocupantes del automóvil sin ventanillas. Protestaron por los destrozos al rodado. Se les preguntó si acostumbraban a usurpar manifestaciones ajenas, al modo de Lanusse respecto al gobierno de la nación. Prometieron volver, suponemos que para discutir, ya que en las calles hay demasiadas piedras. Nos llama la atención el hecho, porque también en el acto de Trelew, ante cuatrocientos trabajadores, integrantes de la Juventud Peronista llegaron intempestivamente y pretendieron hablar" (Irquierda Popular, núm. 4, 16 a 30 de octubre de 1972, p.7, subrayado nuestro).

Los principales enfrentamientos por la dirección barrial, especialmente desde 1974, se suscitarían más bien con los sectores de la derecha peronista; que además de servirse de la violencia armada para dirimir las disputas políticas, conforman también nuevas y paralelas Juntas Vecinales que rápidamente serán institucionalizadas, desarticulándose así las primigenias organizaciones autónomas $^{14}$ (Barberena et al, 2011).

La masacre del 22 de agosto de 1972, y la pueblada del 11 de octubre de ese mismo año, acontecen en pleno proceso de expansión barrial y organización política (vecinal), cuya politización adoptará especial efervescencia entre 1973 y 1976. Una de las primeras muestras de esa creciente organización barrial y de su capacidad de movilización popular, tuvo lugar el 8 de octubre de 1972, cuando el FIP organizó

“un acto en un viejo galpón del Barrio La Laguna, que contó con una concurrencia de 400 pobladores. Hablaron los compañeros Such y Medrano y un compañero del barrio y el clima de entusiasmo no decayó durante las dos horas que duró el acto. Al finalizar el mismo, los compañeros presentes, constituidos en asamblea, decidieron formar la Junta Popular del Barrio La Laguna, adherida el Frente de Izquierda Popular" (Irquierda Popular, núm. 4, 16 a 30 de octubre de 1972, p.7)

Por su parte, el diario Jornada consigna que en ese acto los oradores remarcaron

"la necesidad de la organización revolucionaria de la clase trabajadora para asegurar que el movimiento nacional responda a los verdaderos intereses de sectores populares y no a minorías privilegiadas. La única seguridad de esa salida, parte entonces de la participación activa del pueblo en las grandes soluciones nacionales, para la cual debe contar con dirigentes de base comprometidos y decididos a defender los intereses populares a cualquier precio" (Diario Jornada, 9/10/1972).

presencia barrial de esta organización política puede rastrearse al acto de bienvenida a Héctor Cámpora en el Aeropuerto de Trelew, en julio de 1972. Allí pudo observarse la militancia barrial con una bandera con la siguiente inscripción: "Los prisioneros de guerra se liberan con la guerra. Juventud Peronista. La Laguna" (Archivo fotográfico Diario Jornada, 9/07/1972).

${ }^{14}$ En 1973 se reglamenta (bajo ordenanza 323) el funcionamiento de las Asociaciones Vecinales y en 1974 se comienza a subdividir el "Barrio Norte", dando lugar al barrio Pte. Perón (ordenanza 388/74) y Oeste (Irusta y Rodriguez, 1993: 138) 
Tres días más tarde las fuerzas armadas llevarían a cabo el "Operativo Vigilante", abriendo paso a la rebelión popular:

"El 8 de octubre el Frente de Izquierda Popular realizó un acto público en el barrio La Laguna, al que asistieron 400 personas entre trabajadores y pobladores de la populosa barriada. Este hecho fue una de las excusas para que las fuerzas de ocupación que a la fecha han sido aumentadas al desproporcionado número de 7.000 hombres, desataran el operativo de 'caza de brujas' que terminó con la detención de 16 ciudadanos" (Izquierda Popular, núm. 5, 26 de octubre al 9 de noviembre de 1972, p.6)

\section{Sistema represivo, militarización de la sociedad y comisiones de solidaridad}

La estrategia de dominación y control social de la Revolución Argentina, (esto es la política represiva que instrumentan las FFAA), se orientó en principio a contener la movilización social, la huelga de masas y las insurrecciones populares; y ad-hoc fue combinando (sobre todo postcordobazo) una táctica represiva, crecientemente clandestina y terrorista, para eliminar la "subversión" y desarticular el aparato político de las organizaciones armadas.

En ambos casos las medidas de "seguridad" siempre buscaron descentralizar las fuerzas políticas opositoras y romper sus organizaciones, para dividir sus cuerpos y aislar al "enemigo interno". La estrategia del poder históricamente ha tendido a obturar las relaciones sociales que entrelazan sectores opositores, para restarles fuerza material y capacidad organizativa.

Los reglamentos de contrainsurgencia dan cuenta de las tácticas y de la preparación que reciben las fuerzas armadas para combatir una protesta social. ${ }^{15}$ En el Reglamento Codificado 8-3 del Ejército Argentino (1969), se la conceptualiza como "subversión urbana" entendiendo por ello

"una manifestación principal o muy importante de la actividad enemiga que ya ha sobrepasado a las fuerzas de seguridad (...) La subversión urbana será, por naturaleza, relativamente rápida, inflamatoria y destinada a enardecer y provocar un descontento agudo; podrá ser general o quedar localizada en determinados sectores humanos (gremios, estudiantes, etc.)" (RC 8-3: II, 1). ${ }^{16}$

El reglamento también distinguía según el tipo, entre: disturbio civil, insurrección urbana, muchedumbre, manifestación ${ }^{17}$, turba ${ }^{18}$, tumulto $^{19}$, guerrilla urbana. El principal objetivo era la contención y/o disuasión de las grandes multitudes para propagar su "energía movilizadora" (Escobar y Velázquez, 1975) y restarle fuerza social al campo opositor.

\footnotetext{
15 Sobre RC-2-1 (Conducción para las fuerzas terrestres), RC-2-3 (Zonas de Emergencia) RC 8-2 (Operaciones contra fuerzas irregulares), RC-8-3 (Operaciones contra la subversión urbana), RC-15-80 (Prisioneros de Guerra), RC-5-2 (Operaciones sicológicas) y RC-9-1 (Operaciones contra elementos subversivos) ver en Pontoriero, Esteban, "El tratamiento de los prisioneros de "guerra subversiva" en los reglamentos de contrainsurgencia del Ejército argentino (1955-1976)”, Revista www.izquierdas.cl, núm. 19, 2014, pp. 131-142.

${ }^{16}$ Ejército Argentino (1969), RC 8-3 “Operaciones contra la subversión urbana”: Instituto Geográfico Militar. En línea: $\% 20 \mathrm{Manual} \% 20$ Operaciones $\% 20$ Urbanas.pdf) http://www.ruinasdigitales.com/revistas/dictadura/Dictadura $\% 20$ -

17 “... ( o demostración) Es una multitud sicológicamente unificada en virtud de un interés común. Se caracteriza por estar organizada, y exteriorizar sus sentimientos hostiles o de apoyo a determinadas personas, causas o situaciones políticas, económicas o sociales.” (RC 8-3: III)

18 "Es una multitud desordenada, aparentemente fuera de control. Actúa bajo el estímulo de una intensa excitación o agitación, pierde el sentido de la razón, el respeto a la ley y pasa a obedecer a individuos que toman la iniciativa de dirigir acciones desatinadas y delictivas" (RC 8-3: III)

19 "Desacato al Orden, llevado a cabo metódicamente por una multitud en apoyo de un objetivo común; se realiza mediante una acción planeada contra las personas o bienes que se desea vulnerar" (RC 8-3: III)
} 
Pero el fusilamiento de 16 presos políticos el 22 de agosto en la base A. Zar de Trelew, marca un punto de inflexión en la estrategia represiva del régimen: "a partir de ese momento entramos en una situación distinta. Hubo un salto cualitativo en la represión ilegal que nos llevó a interpretar que estábamos ante lo que llamamos muchas veces, el doctor Duhalde y yo, el «Ensayo general del Terrorismo de Estado»" (Rodolfo Mattarollo, 2012). Desde la Masacre de León Suárez (1956) que el Estado no cometía un asesinato en masa de esta índole. ${ }^{20}$

La represalia (contraofensiva) del régimen militar ante la fuga de prisioneros del penal U6 el 15 de agosto de 1972, se expresaría primero en la Masacre de Trelew y luego -50 días más tarde- durante el Operativo Vigilante. No sólo constituyen las primeras acciones explícitas de violencia contrarrevolucionaria $^{21}$ en la región, sino que representan -por sobretodo- actos fundantes de un embrionario sistema de terror.

A la legislación "anticomunista" 22 y a las prácticas clandestinas de contrainsurgencia (simulacros, operativos, infiltraciones, secuestros, torturas) que hacían a la estrategia represiva, se suman ahora en Trelew la ejecución extrajudicial de prisioneros y los mecanismos posteriores para encubrir el crimen y deslindar responsabilidades ${ }^{23}$. El mensaje de terror completa la escena. Dos semanas después de perpetrada la Masacre, el capitán de navío Horacio Mayorga dirigió (al personal y a la sociedad trelewense en general) un amenazante discurso desde la Base Zar:

"Los hechos ocurridos (en Trelew) han despertado dos actitudes en la gente que nos rodea. Unos pretenden acusar a la Armada de haber provocado una masacre intencional. Los otros, ante el hecho consumado, lo justifican y hasta lo aplauden, dada la peligrosidad de los presos. $\mathrm{Ni}$ unos ni otros tienen razón. La Armada no asesina. No lo hizo, no lo hará nunca. Se hizo lo que se tenía que hacer. No hay que disculparse porque no hay culpa. No caben los complejos que otros tratan de crear. La muerte de seres humanos es siempre una desgracia. Estos muertos (alude a los sediciosos) valen menos, en el orden humano, que el guardia cárcel Valenzuela (muerto el 15 de agosto en el operativo de fuga de la conducción guerrillera), que los humildes argentinos del orden público muertos en servicio." (La Prensa, 6 de septiembre de 1972).

\footnotetext{
${ }^{20}$ El capitán Luis Emilio Sosa, uno de los principales responsables de los fusilamientos en Trelew (condenado a cadena perpetua en 2012 por crimen de lesa humanidad), integraba el Batallón de Infantería de Marina BIM 4, fuerza que en 1956 había participado también de otro crimen de Estado como lo fue el bombardeo a Plaza de Mayo.

${ }^{21}$ La violencia contrarrevolucionaria es ante todo una política represiva de carácter defensivo (Marín, 2009). La caracterización de "contrarrevolucionario" le imprime especificidad (e historicidad) al sistema represivo. Si bien el contenido coercitivo del Estado capitalista es invariable, lo que cambia es su morfología acorde a las circunstancias históricas. El carácter contrarrevolucionario, no refiere tanto a la cuestión de si estaba en ciernes o no un real proceso revolucionario, sino a las acciones y modificaciones que ante esa hipótesis asume el Estado para etiquetar, reprimir y anular toda resistencia y oposición social que viniese a obstaculizar el programa de gobierno de las FF.AA. Es la violencia característica que ejerce un Estado de tipo Contrainsurgente (R. Marini, 1978) para ordenar la economía (en función del sector monopolista) y controlar las luchas sociales. No perdemos de vista que el fundamento principal del Estado capitalista es el monopolio de la violencia; lo que nos interesa observar es como ese Estado debe reorganizar (en función de la coyuntura histórica y de la situación de la lucha de clases) el conjunto de sus aparatos institucionales, administrativos y legales de los que se vale para tal fin represivo (esto es, la represión de las insurrecciones populares, el movimiento de masas, las huelgas obreras y el accionar de las organizaciones armadas). Denominar esa violencia como contrarrevolucionaria nos permite situar la especificidad del periodo para diferenciarla así de la represión estatal en otros contextos históricos, como por ejemplo, el de la post-dictadura.

${ }^{22}$ Decreto-ley 16.984 de 1966 (prohibía la distribución por correo de propaganda "comunista”); ley 17.401 de 1967 (de represión al "comunismo" y a la "subversión”); ley 18.234 de 1969 (modificación a la 17.401 que sanciona hasta la actividad ideológica); ley 18.799 (reducción de hábeas corpus) de 1970; la ley 19.081 de 1971, que autorizaba a las FF.AA en operaciones de seguridad interior o la ley 19.053 del mismo año, por la cual fue creada la Cámara Federal en lo Penal, entre otras.

${ }^{23}$ En concreto, el decreto-ley 19.797 del 22/8/1972 que penaba a todo aquel que difundiera imágenes o cuestiones relacionadas a los militantes políticos, y a la Masacre de Trelew, obligando a difundir las versiones oficiales del hecho. Por este decreto, Tomás Eloy Martínez fue despedido de la revista Panorama luego de publicar irregularidades y contradicciones entre las distintas versiones oficiales.
} 
La militarización de la sociedad bajo la "Zona de Emergencia" desde la fuga/masacre de agosto, la persecución ideológica y el hostigamiento reflejados en el Operativo Vigilante del 11/10/1972, y la plena vigencia del PLACINTARA ${ }^{24}$ (Plan de Contención Interna de la Armada), son otros de los elementos que nos llevan a pensar que estamos en presencia de un embrionario sistema de terror o ante un "ensayo general" de Terrorismo de Estado.

Resta destacar en este escenario represivo, la creciente centralidad de los órganos de inteligencia. La información que acumulan las distintas agencias del Estado, es el combustible de la maquinaria represiva y el principal insumo para la persecución ideológica. Tanto sus mecanismos "legales" (aparato jurídico) como los ilegales (prácticas "clandestinas" de contrainsurgencia) se asientan en gran medida sobre la información que se construye, recaba y organiza en torno a la figura del "enemigo interno". Los servicios de inteligencia, y la comunidad informativa que estructuran, aportan la principal materia prima para organizar y coordinar la represión en este periodo.

Luego de la Masacre de Trelew (siete semanas después), el segundo acto de violencia contrarrevolucionaria es el Operativo Vigilante; y la Comisión de Solidaridad con los Presos Políticos (CSPP) representa el nexo y la continuidad entre las violencias de agosto y octubre en Trelew. Al catalogarlos como actos explícitos de violencia contrarrevolucionaria, buscamos diferenciarlo de un mero acto represivo y otorgarle especificidad histórica. En esos dos episodios se expresa la ofensiva contrainsurgente y anti-insurreccional de la dictadura cuya finalidad es desmovilizar y dispersar a la sociedad.

\section{Las Comisiones de Solidaridad}

Paradójicamente, muchas veces las tácticas "desmovilizadoras" y militaristas en pos de la "Seguridad Nacional", acabaron retroalimentando -directa o indirectamente- la fuerza social que buscaban reprimir. Así lo entendían también las propias fuerzas represivas:

"Estas actividades (investigación y detenciones) podrán molestar e irritar a ciertos sectores de la población; pero la responsabilidad de estas medidas deberá ser imputada a los elementos subversivos. Por otra parte, será necesario hacer todo lo posible para que estas actividades no resulten tan severas que puedan estimular a los civiles a colaborar, por resentimiento con el enemigo" (RC 8-3: 90)

La estrategia para aislar a los presos políticos en la Patagonia argentina, buscaba romper los lazos solidarios y políticos que envolvían a los militantes presos: sus abogados, sus familias y amigos, compañeros, etc. ${ }^{25}$ No obstante, ello generó localmente un núcleo de politización y de

\footnotetext{
${ }^{24}$ Las pruebas documentales presentadas en el juicio por la Masacre de Trelew (2012), permiten inferir desde mediados de 1972, la vigencia de ese plan de "capacidades". PLACINTARA estipulaba la organización interna para la represión. En él se divide a la Armada en 11 fuerzas, siendo la Fuerza de Tareas no 7 la asignada al NE de Chubut; su jefatura la Base Zar de Trelew. Integraban la FUERTAR 7 -denominada AGRUPACIÓN TRELEW- el Batallón de I.M. No 4, el Apostadero Naval Golfo Nuevo, la Prefectura Madryn, la Prefectura Rawson y las dependencias de la Armada y Prefectura Naval Argentina en la Zona de Trelew, Rawson, Golfo Nuevo, Península Valdéz y zonas portuarias de Madryn y Rawson; Departamentos de Telsen, Gastre, Gaiman, Viedma y Rawson de la Provincia de Chubut.

25 “Las modificaciones introducidas en el sistema legal reducirán el tiempo de cada proceso, evitarán la concentración de extremistas y dificultarán la comunicación entre la dirección insurreccional -parcialmente detenida- y sus cuadros. Teniendo en cuenta la responsabilidad directa en el control operacional de las Unidades Carcelarias por parte de las Fuerzas Armadas, se hace necesario extremar las medidas de seguridad en dichos establecimientos, ya que una eventual fuga produciría importantes dividendos psicológicos para la subversión, a la vez que implicaría una seria aunque circunstancial- derrota para el Gobierno y las FF.AA." (Armada Argentina, "Informe Periódico de Inteligencia del 1/10/71 al 15/5/72", -documento interno de la fuerza, presentado como prueba en el juicio por la "Masacre de Trelew"-, 2012)
} 
participación social en torno al dispositivo U6 que tuvo como principal materia prima la solidaridad con los presos políticos.

La primera Comisión de Solidaridad la forma el sindicato de Luz y Fuerza de Trelew, en junio de 1969, ante el traslado de los presos políticos y gremiales del Cordobazo; en 1971, se organizan familiares, amigos, docentes y profesionales de la zona en torno a la detención de Ángel Bel, militante comunista de Trelew; ${ }^{26}$ en septiembre de ese mismo, se conforma la Comisión de Solidaridad con los Presos Políticos (CSPP), y el 20 de agosto de 1972, se organiza una Comisión por la Libertad de Mario Abel Amaya, abogado trelewense defensor de presos políticos y miembro de la Gremial de Abogados.

La Comisiones de Solidaridad, y especial la CSPP, permitían romper el aislamiento de los presos políticos a la vez que generaba todo un movimiento en la sociedad local que se organiza para tales fines. En torno suyo se fueron tejiendo nuevas relaciones sociales que promovían el contacto solidario y horizontal entre personas. Los servicios de inteligencia del Estado advirtieron rápidamente esta nueva forma de actividad política:

"Desde el mes de setiembre de 1971, fecha en que es trasladado para su alojamiento en la Unidad Carcelaria de Rawson un grupo de detenidos subversivos, se suscitan en la zona Rawson, Trelew, Madryn- una serie de acontecimientos que perturban en cierto modo la tranquilidad de la zona, aunque no se han registrado hasta el presente hechos o acciones de corte subversivo propiamente dicho. Inmediatamente de concretado el traslado de los detenidos, bajo el auspicio de elementos izquierdistas y peronistas de línea dura, se organiza la "Comisión de Ayuda y Solidaridad con los Presos políticos y Sociales de Rawson". Hasta el momento, la única actuación de la mencionada comisión ha sido la de promover manifestaciones y declaraciones públicas, "Solicitadas" en los diarios locales y cierta ayuda a los familiares de los detenidos que generalmente son provenientes de la provincia de Córdoba”. (Armada Argentina. Informe Periódico de Inteligencia del 1/10/1971 al $15 / 5 / 1972){ }^{27}$

Los miembros de la Comisión de Solidaridad visitaban una vez por semana a los presos políticos del penal de Rawson. Cada persona tenía asignado a un detenido, llevándole medicamentos, ropa, cartas, etc. Incluso muchos sus integrantes y/o allegados, alojaron y dieron contención en sus casas a los familiares de los detenidos que lograban llegar a la zona. ${ }^{28}$ Coincidimos con Murphy (2017) al observar que la cárcel de Rawson abre un espacio de politización en torno a las acciones

\footnotetext{
26 "Habitantes de la provincia del Chubut se encuentran privados de su libertad y alojados en la cárcel de Rawson como medida represiva por sus ideas./ Los abajo firmamos, conscientes de la arbitrariedad que significa encarcelar a un ser humano por lo que ha querido llamarse delito de pensar, característica ésta de la raza humana y dentro de ella de los hombres que independientemente de su profesión política, luchan por un mundo mejor, reclamamos su inmediata libertad./ (...)Abran las cárceles a quienes vieron adonde conducía esa conducta y tuvieron el valor de predecirla y más aún expresarla!/ Hoy ya nadie calla. Que el libre juego de las ideas eche a correr. Que los hombres todos sean los responsables de un destino. Que quien los gobierne lo haga por mandato popular/ Abra el gobierno ya las cárceles si como ha manifestado es su intención pacificar y llamar a todos los argentinos a participar en el quehacer nacional" (Diario Jornada, 4/5/71)

${ }^{27}$ documento interno de la fuerza, presentado como prueba en el juicio por la "Masacre de Trelew" (2012)

28 "desplegaron un conjunto de prácticas e iniciativas alrededor del vínculo y contacto con los familiares. Estas tenían que ver con el apoyo logístico y la puesta a disposición de infraestructura (casas, alimentos, etc.) para quienes venían de visita y carecían de los medios para permanecer en el lugar a la espera de la entrada a la cárcel. Muchos llegaban con limitaciones económicas, tenían un viaje largo y dificultades para poder pagar un alojamiento. La mayoría era gente humilde, ancianas y madres. Esto habilitó la masificación y ampliación de la red de solidaridad local con el objetivo de realizar dicho apoyo logístico". (Murphy, 2017: 61). Para ampliar sobre la CSPP ver: Fernández Picolo, "Los presos políticos en Rawson y la Solidaridad", op. cit.; González Canosa, "La Comisión de Solidaridad con los presos políticos y sociales de Rawson y los apoderados legos", op. cit.
} 
de solidaridad. Tanto sus miembros como el resto de los "apoderados legales" 29 , eran vecinos de la ciudad con un marcado compromiso social. Muchos de ellos sin filiación partidaria, pero con claras convicciones éticas y políticas; otros directamente provenían del peronismo, de la UCR y del PC, o directamente compartían un ideario socialista. En este contexto, la CSPP constituye un artefacto político, cuya praxis solidaria en pos de la defensa de los DDHH, logra sortear la censura y proscripción que impone la dictadura;

"Para quienes la solidaridad se constituye sin exclusiones, el rechazo a la represión se convierte en reclamo de libertad a los detenidos. En protesta que cuestiona el orden instituido por la dictadura sumándose al movimiento de oposición generado desde las comisiones de solidaridad y en que concluyen las protestas de los barrios, de los jóvenes, de los gremios, como nuevas expresiones de participación”. (Fernández Picolo et. al, 1991: 118)

\section{E1 Operativo Vigilante}

Durante la madrugada del 11 de octubre de 1972, las fuerzas armadas y de seguridad ejecutaron en el NE de Chubut (Trelew, Rawson, Madryn y Pirámides) el "Operativo Vigilante", a cargo del $\mathrm{V}$ cuerpo del Ejército -con sede en Bahía Blanca-. El comunicado que emitieron radialmente exponía:

"Se comunica a la opinión pública que en la madrugada de hoy, 11 de octubre, efectivos del Ejército dependientes de este comando, de la Armada Argentina, de Gendarmería Nacional y de las Policías Federal y Provincial, efectuaron diversos procedimientos en distintos sectores de las ciudades de Trelew, Rawson y Puerto Madryn. Esta actividad ha sido desarrollada para garantizar el orden y la tranquilidad pública de la comunidad de Trelew que ha sido directamente afectada por la acción de elementos vinculados a actividades subversivas. En consecuencia, de acuerdo a lo establecido en la Ley $19.081^{30}$ y en atención a diversas denuncias realizadas por distintos sectores de la población y las investigaciones efectuadas, se han dispuesto los procedimientos mencionados'. (Firma: Gral. Aníbal Medina, segundo

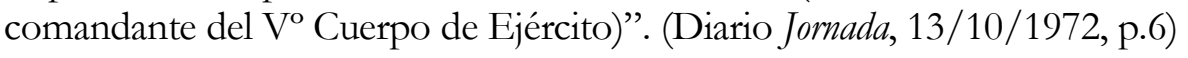

Atendiendo al reglamento de "Operaciones contra la subversión urbana" que regía al V cuerpo estipulaba, podríamos catalogar el operativo de Trelew como una "incursión", esto es una "operación, normalmente de pequeña envergadura, que consiste en atacar por sorpresa al enemigo con el objeto de obtener información, producirle bajas y confusión o destruir sus instalaciones" (RC 8-3: 73).

Durante el operativo se allanaron cientos de domicilios particulares; muchos pertenecían a los "apoderados legales" de los presos políticos, cuya lista ascendía a más de 50 (Ibarra y Hernández, 2016) o a gente vinculada con las comisiones de solidaridad. Se realizaron decenas de detenciones, y finalmente se llevaron secuestrados a 16 personas (sin orden judicial a Villa

\footnotetext{
29 "ante la dificultad de actuación de los propios abogados de los detenidos dado su aislamiento, distintos pobladores de Trelew gestionaron poderes ante una escribanía que les permitieron convertirse en sus "apoderados legos", es decir no abogados. Esto les permitía representarlos, hacer gestiones en su nombre, encontrarse con los detenidos en el penal una vez por semana, charlar con ellos y llevarles lo que necesitaran (González Canosa, 2005: 42).

${ }^{30}$ Este decreto del 16/6/71 firmado por Lanusse, dotaba de respaldo jurídico a los militares para actuar en territorio propio: "Facúltese al Poder Ejecutivo Nacional a emplear durante la vigencia del estado de sitio en el territorio de la Nación, en sus aguas jurisdiccionales y su espacio aéreo, las fuerzas armadas que considere conveniente en operaciones militares, a fin de prevenir y combatir la subversión interna, el territorio y demás hechos conexos.”. En el art.4, fijaba que las policías y demás FFSS quedarían bajo control operacional de los respectivos comandos militares, "ejecutando las funciones, misiones y tareas que se les impongan". La zona queda de facto bajo control total de las FFAA.
} 
Devoto). Todos ellos tenían algún grado de participación o de vinculación con el movimiento de solidaridad política, lo que les valió la infundada acusación de haber colaborado con la fuga y de estar implicados en "actividades subversivas". Las personas detenidas bajo sospecha de subversión, eran consideradas -según el reglamento de la fuerza armada- miembros de "un movimiento de insurrección urbana que [trataba] de ejercer un control psicológico y físico sobre la población. Dicho control lo logrará por una red de dirigentes que operará de manera abierta o encubierta en las distintas manzanas o barrios de la ciudad" (RC 8-3: 38). Por razones estratégicas, consideraban "de particular importancia el ubicar: los lugares favorables para el ocultamiento y/o actuación del enemigo (villas de emergencia, universidades, fábricas, sectores no urbanizados, etc.).

Según explicarían las FF.AA. con el correr de los días, las detenciones se enmarcaban en el "proceso de investigación que se desarrolla actualmente en averiguación del plan de intimidación pública programado por distintos elementos subversivos para los próximos días" (Diario Jornada, 17/10/1972, tapa. Subrayado nuestro). Esto se ajustaría a la "recomendación" del Reglamento Codificado de que "en el caso de una inminente alteración del orden público el arresto anticipado de sus jefes y de los activistas contribuirá enormemente a desarticular las acciones del enemigo" (RC 8-3: 92).

Los oficiales del V cuerpo del Ejército que interrogaron a los detenidos en Devoto, en repetidas ocasiones hicieron hincapié en supuestos actos que se programaban para el día de la "lealtad peronista": Lendzian declararía ante la prensa que "le dijeron durante el interrogatorio de que los habían detenido en prevención de 'actos contra la propiedad privada' que se llevarían a cabo el 17" (Diario El Chubut, 24/10/1972). A Del Villar le preguntaron si, "¿Tenía conocimiento de los movimientos que se programaban para el día 17?”; mientras que a Echeverría, le preguntaron sí “¿Sabía que en Trelew se estaba gestando un gran movimiento de fuerza para los días 17 y 18 ? (Diario Jornada, 18/10/1972. p.4). Claramente la capacidad de articulación política y de movilización popular era algo que especialmente preocupaba al régimen

Durante esa mañana del 11 de octubre, se bloquearon las rutas de acceso a esas ciudades, y se registró minuciosamente cada uno de los vehículos que por allí circulaban (muchos de los cuales iban hacia sus lugares de trabajo). Los camiones del ejército patrullando las calles; los retenes y los soldados apostados; los vuelos rasantes, el avión Hércules C-130 en el aeropuerto de la ciudad y la instalación allí de tiendas de campaña, generaban un particular clima de incertidumbre y tensión, dando todo el aspecto de una ciudad "tomada".

La estrategia del poder provincial (y en general de los sectores alineados con la dictadura, como sindicatos y prensa) será ante todo buscar desmovilizar y desactivar la protesta popular para encausarla institucionalmente (Pérez Álvarez y Binder, 2019). Esa misma noche, el interventor Jorge Costa emitió un mensaje ${ }^{31}$, desvinculando de cualquier responsabilidad al Estado provincial y relacionando el operativo "Vigilante" con la Masacre de agosto, buscó enmarcarlo como una medida más de "seguridad nacional", tal como indicaba el RC 8-3:

“el enemigo necesitará hacer participar a la población y lanzarla como instrumento capaz de realizar sus propósitos, con el objeto de: desmoralizar a las autoridades legales, producir la caída del gobierno y conquistar el poder. Le corresponderá por lo tanto al gobierno movilizar a la opinión pública a su favor mediante una conveniente campaña de acción

\footnotetext{
31 "lamentando los episodios vividos en la ciudad de Trelew el 22 de agosto pasado, cuyos efectos promovieron los procedimientos realizados el miércoles y los explicó diciendo que habían sido ordenados por la autoridad militar, aclarando que en él no tuvo participación el gobierno de la provincia. Expresó que la seguridad de la población reclamaba este tipo de acciones preventivas y formuló un llamado a la comprensión ciudadana para tolerar las molestias circunstancias en que los mismos se llevan a cabo" (Diario Jornada, 13/10/1972, p.7)
} 
sicológica, teniendo en cuenta la necesidad de preservar el orden y conseguir el repudio del enemigo interno" (84)

Pero la zozobra que provocaban las intimidaciones de las FFAA y la complicidad del Estado provincial, no fue suficiente para paralizar la acción política; menos aún para desmovilizar la reacción popular en una región que, desde la fuga del penal U6 en agosto, había sido declarada "zona de emergencia". El "objetivo básico de aislar a la población del enemigo" (RC 8-3: 21) que persiguió el Operativo Vigilante al secuestrar a 16 habitantes separándolos de la comunidad (en Devoto), paradójica e inversamente, indujo una reacción defensiva y en masa de esos vínculos.

"El Pueblo" demostró en las calles su fuerza social acumulada, y en el Teatro Municipal desarrolló una praxis política asamblearia, horizontal autónoma y autogestiva. La "Asamblea del Pueblo", dispositivo propio de la clase obrera, fue el principal mecanismo deliberativo de la fuerza opositora. $\mathrm{Y}$ esa organización alternativa y experiencia de democracia directa, sin mediaciones y más radicalizada, era precisamente lo que se buscaba castigar y "domesticar". El Operativo Vigilante, a siete semanas de la Masacre de Trelew, apuntó a romper las relaciones sociales de autonomía y de solidaridad política entre sectores del proletariado y de la pequeña burguesía.

Las posiciones de ataque y defensa ${ }^{32}$ son operadores metodológicos que nos permiten analizar las correlaciones de fuerzas (Marín, 2009: 82) y ponerle orden a la trayectoria dialéctica de los hechos de violencia, identificando los usos tácticos y sentidos estratégicos detrás de cada episodio. Esto nos permite ir estableciendo posibles conexiones dialécticas entre las los principales hitos (y "violencias") del periodo en la región: así concebida, la masacre del 22 de agosto Trelew constituye una "respuesta" defensiva del poder militar ante la afrenta que significó la fuga del 15; y el Trelewazo, es la respuesta defensiva del pueblo al ataque que significó el Operativo Vigilante de octubre. La masacre de agosto representa el primer acto de terrorismo de estado y en la pueblada de octubre, por primera vez una movilización popular le "arrancó" presos políticos a la dictadura de la "Revolución Argentina", haciéndola retroceder aún más.

\section{Conclusiones}

En el Trelewazo, el sector obrero migrante que conforma las barriadas populares, se integra a un movimiento colectivo de protesta que es la expresión política de una fuerza social (de masas) opositora. Sin esta fracción del proletariado, no hubiese habido pueblada posible; fue la sumatoria de esos cuerpos la que permitió revertir la relación de fuerzas con el régimen y conseguir la liberación de los presos políticos. Esta "nueva" fracción de la clase obrera surge, desde 1969, de las transformaciones en la estructura económico-social y sus fenómenos derivados.

Uno de ellos fue que la dinámica explosiva del desarrollo local -regida por la industrialización asistida-, alentó un boom migratorio que generó un patrón de asentamiento espontáneo en las márgenes de la ciudad, donde la carencia de servicios básicos -cómo la luz o el agua- se solapaba con una larga serie de demandas sociales y habitacionales insatisfechas. De esos barrios proviene el principal aporte de cuerpos que hizo posible el hecho de masas.

\footnotetext{
32 "El ataque procura la apropiación, la alteración de una relación social, mientras que la defensa pretende la preservación de una relación y por lo tanto dirige toda su fuerza a la acción del oponente. Por esta razón, es precisamente este último gesto el que desata, en términos estrictos, el inicio del conflicto" (Pierbattisti, Damián y Rebón, Julián, "Introducción”, Cuaderno 8 ed. PICASO, 2009, subrayado nuestro). Metodológicamente, Marín explica que "ataque" constituye "Toda acción, todo proceso, toda secuencia que altere las relaciones sociales de un espacio social. Y defensa es todo proceso que tenga como consecuencia el restablecimiento de las condiciones iniciales de ese espacio social. Este modelo tiene una virtud: una gran universalidad de aplicación”. (Marín, 2009:83)
} 
Su problemática de clase, no se circunscribía en lo inmediato a la relación obrero/patrón, sino a los problemas derivados de su situación de marginalidad producto de una urbanización no planificada. Por más que sus demandas parezcan de corte "ciudadano" o vecinal, hacen esencialmente a su condición de clase obrera y a las dificultades que enfrentan para vivir y reproducirse. Y su consolidación como fuerza política se estructura en torno a la necesidad de hacer frente a los problemas cotidianos del barrio y a sus hostiles condiciones de vida.

H. Lefebvre (2013) veía al espacio urbano como el ámbito principal en el que se realiza la reproducción de la fuerza de trabajo, y M. Castells (1988), afirmaba que la vivienda era uno de sus elementos centrales; definiría al proceso de planificación urbana como "la intervención de lo político sobre las diferentes instancias de una formación social (incluido lo político) y/o sobre sus relaciones, con el fin de asegurar la reproducción ampliada del sistema" (Ordovás, 1998: 317). En suma, los problemas que de allí se derivan y su búsqueda de solución, hacen a la relación de fuerzas y a la lucha de clases, pero desde el ámbito reproductivo de las relaciones sociales. (Martínez López, 2003).

Fueron esos problemas derivados de la materialidad de sus condiciones de vida el principal mecanismo de politización, y no la protesta (Trelewazo) en sí. Las comisiones barriales, son el observable empírico que así lo sugiere. ${ }^{33} \mathrm{Y}$ la organización asamblearia, la herramienta deliberativa que da curso a esa politicidad, habilitando una experiencia de participación alternativa, diferente de la electoral.

En este sentido, coincidimos con González Canosa, cuando sostiene que "en este contexto de cambios, más allá de los partidos políticos, se genera en la región cierta activación social y política que si bien puede articularse con ellos en algunos casos, excede sus canales de participación" (2005: 35. Subrayado nuestro). Pero disentimos con ella cuando sostiene que la protesta no debe reducirse al principio unificador último de la lucha de clases (2005: 30, 116). Para nosotros, la participación política de los barrios durante el Trelewazo (en asambleas y en movilizaciones) expresa una de las tantas facetas que puede asumir la lucha de clases en un conflicto determinado. Que el mismo se presente y exprese lejos del ámbito del capital, sin que se tensen directamente las relaciones de producción, no lo convierte en un episodio ajeno a la lucha de clases. Si bien el Trelewazo constituye una lucha de tipo política, el factor económico que -aparece subsumido- es también constitutiva de la misma:

1) porque la fuerza política que mayor número de personas que moviliza proviene de la clase obrera, y en especial de los nuevos trabajadores migrantes que atrae el proceso de promoción industrial.

2) porque su politización, expresada en las organizaciones barriales, se deriva de los problemas que trae aparejado el boom industrial, que a su vez es resultado de una estrategia específica de acumulación, en clave de "seguridad nacional".

3) porque la estrategia de dominación expresada en el Operativo Vigilante, refleja que apuntaba a desarticular las Comisiones de Solidaridad y a perseguir a los apoderados legales, buscando romper las relaciones sociales de solidaridad política. Los derechos humanos, eran, desde nuestra perspectiva y en este contexto, un insumo para la lucha política (de clases) del momento, pero no gestora de la misma. Además, los presos políticos y su traslado al sur, eran el resultado de la política represiva que la dictadura instrumentó para asegurar el interés del capital monopolista y

\footnotetext{
33 "La actividad de estas comisiones comenzará a ganar un espacio relevante en el marco de las prácticas comunitarias, excediendo a su vez dicho ámbito para convertirse en una cuestión de debate en el seno de la sociedad trelewense. Además, a partir de la experiencia acumulada en las asociaciones vecinales y de la actividad de diversos militantes políticos en estas zonas, progresivamente las demandas puntuales comienzan a adquirir un carácter social más amplio". (González Canosa, 2005: 35).
} 
de la gran burguesía nacional, en un contexto de crisis orgánica (hegemonía) y de ascenso de la lucha de clases.

Se trata entonces de inscribir esa forma de enfrentamiento social históricamente situada (llámense puebladas, "azos", movimientos de masas, insurrecciones populares, etc.) dentro del proceso general de acumulación de capital (y de pauperización de las clases populares) que va cargando de contenido las luchas sociales, y alentando procesos de formación de poder (y acumulación de fuerza) en los sectores subalternos. Las puebladas son tan solo una de las formas que asume la lucha de clases en el periodo. Antes que reducir el fenómeno, se busca entender cómo se inserta en una totalidad aún más grande que la condiciona. Para ello es necesario atender a la dimensión estructural, tanto en lo que hace a la promoción industrial como al sistema represivo.

Las políticas que CONASE y CONADE instrumentaron, en buena medida fueron delineando el "escenario" y los "repertorios" de acción que asumirían las luchas sociales en la región. La industrialización acelerada del NE de Chubut desde fines de 1969, combinado con la incorporación del penal U6 a la estrategia represiva de la dictadura transformaron las relaciones sociales y dinamizaron sus prácticas políticas. El "Polo de Desarrollo" (industrialización) y la "zona de emergencia" (militarización) influyeron y condicionaron la forma regional que asumió la lucha de clases general del periodo.

Las "comisiones de solidaridad", fueron la respuesta "autóctona" a ese entramado represivo que se va montando regionalmente; y el Operativo Vigilante la respuesta militar para castigar y horadar esas relaciones sociales. La solidaridad constituye una de las armas morales ${ }^{34}$ de los expropiados y oprimidos; es una argamasa que permite vincular cuerpos y acumular energía para conformar fuerza política. Metafóricamente, la solidaridad es lo que el cemento a los ladrillos de la pared. Y el ataque a esas relaciones "solidaridarias" dinamizó las contradicciones políticas y precipitó la situación de masas en Trelew. No es que haya sido su fundamento; sino más bien el percutor que abrió un espacio de protesta común sincronizando la lucha previa de vastos sectores de la sociedad, y liberando la presión política acumulada

La injusticia explícita en los fusilamientos en la Base Zar de Trelew (que evidencian la naturaleza represiva y criminal del régimen) se combina con la certeza de la legitimidad del reclamo popular, alimentando una fuerza moral que empuja a la acción colectiva. Es esa convicción "la que le otorga materialidad a la fuerza moral contenida en esa fuerza social de enfrentamiento". (Balvé, 1989: 146). La militarización de la región influyó rápidamente en el "humor" de la sociedad, y lejos de paralizarla, más bien indujo una bronca e incomodidad generalizada que incrementó la oposición y el rechazo a la dictadura militar. El "Operativo Vigilante" fue el acto represivo que permitió articular las disidencias y acabó estimulando precisamente eso que buscaba limitar: la movilización popular. Y esa respuesta popular de masas no hubiese sido capaz de alterar la relación de fuerzas, sin la participación de los trabajadores que migraron al naciente polo textil de Trelew.

El desafío teórico radica entonces en poder enmarcar la coyuntural reacción popular dentro de los parámetros más generales (estructurales y orgánicos) del proceso de acumulación que rigieron y dinamizaron la lucha de clases del periodo. Esto supone pensar la situación de masas (acontecimiento) cómo síntesis histórica de múltiples determinaciones (como "unidad de lo múltiple" ${ }^{\prime 35}$ ). Las contradicciones que se manifiestan en el NE de Chubut, abrevan tanto de su condición de polo industrial como de polo represivo. En octubre de 1972, nos encontramos con múltiples problemas y conflictos que se desprenden tanto del "desarrollo" industrial como de la estrategia represiva de "seguridad nacional".

\footnotetext{
${ }^{34}$ La solidaridad, la injusticia o los discursos políticos (por mencionar solo algunos elementos), pueden convertirse en armas morales capaces de generar consenso, agrupar cuerpos, articular fuerzas y predisponer voluntades para la lucha ${ }^{35}$ Karl, Marx, Introducción general a la Crítica Politica, México, Siglo XXI, 1989, p.28.
} 


\section{Bibliografía}

Balvé Beba C., y Balvé Beatriz S., El 69. Huelga política de masas. Rosariazo-Cordobazo-Rosariazo, Buenos Aires, Ed. Contrapunto, 1989.

Barberena, Daniel, Los barrios populares de Trelew en la década del '70, Trelew, Ed. TER, 2009.

Barberena Daniel, Palacios, Dora y Fusiman, Natalia, Los barrios populares de Trelew en la década del 70: el barrio La Laguna (documental), 2011.

Caracotche, Juan Ignacio e Ibarra, Horacio Osvaldo, Plan área central de Trelew (PACT) s/ed, 1973.

Castells Manuel, La cuestión urbana, México, Siglo XXI, 1988.

Cifuentes Valenzuela, A. Transformaciones estructurales del sector productivo en la Provincia del Chubut pos privatización petrolifera (1992-2010), Universidad Nacional de Quilmes, Bernal, 2015. Tesis de Maestría. Disponible en RIDAA Repositorio Institucional Digital de Acceso Abierto http://ridaa.unq.edu.ar/handle/20.500.11807/135

Irusta, Delia y Rodríguez, Lidia "Aportes para el estudio del desarrollo urbano de Trelew", Informe final del proyecto PID-CONICET "Migraciones y desarrollo urbano en Trelew”, 1993.

Escobar, Justo y Velázquez, Sebastián, Examen a la violencia argentina, México, FCE, 1975.

Fernández Picolo, Mauricio, Wester, Wilda y De Oto, Alejandro, "La represión, los presos políticos y la solidaridad. Chubut, 1969-1973”, Informe al CIUNPAT, UNP, 1991.

Gatica, Mónica, ¿Exilio, migración, destierro? Los trabajadores chilenos que se asentaron en el Noreste de Chubut a partir de septiembre de 1973. Memorias, historias e implicancias, Facultad de Humanidades y Ciencias de la Educación, Universidad Nacional de La Plata, 2010. Tesis doctoral. Disponible en: http://www.fuentesmemoria.fahce.unlp.edu.ar/tesis/te.377/te.377.pdf

Hermosilla Rivera, Crisitian, Surai Sotelo, Rebeca, Blanco, Pablo y González Valenzuela, Matías, "Tomas de tierra en el periodo de industrialización de Trelew (1960-1980). Los barrios de la clase obrera a partir de sus memorias y territorialidades", Revista Theomai, núm. 34, Quilmes, 2016.

Hermosilla Rivera, Cristian, "Población Rural En Chubut: La Meseta Desde Principio de Siglo XX a la Actualidad", Párrafos Geográficos, Vol. 12, núm. 1, 2013.

Ibarra, Horacio y Hernández, Carlos, Trelew y su binterland -1889-1999, Colección "Desde Patagonia", Año 1 núm,1, INHIS-UNP, Trelew, Ed. Mandala, 2016.

Lefebvre, Henri, La producción del espacio, Madrid, Capitán Swing Libros, 2013.

Marín, Juan Carlos, Leyendo a Clausemitr: Cuaderno 8, Buenos Aires, Ediciones PICASO, 2009.

Marini R., Mauro, "El Estado de Contrainsurgencia", Intervención en el debate sobre "La cuestión del fascismo en América Latina”, Cuadernos Políticos, núm. 18, México, Ediciones Era, octubre-diciembre, 1978, pp. 21-29. En línea: http://www.mariniescritos.unam.mx/055 estado contrainsurgencia.html

Martínez López, Miguel, "Los movimientos sociales urbanos. Un análisis de la obra de Manuel Castells", Revista Internacional de Sociología, Tercera Época, núm. 34, enero-abril, 2003, pp. 81-106.

Mattarollo, Rodolfo, Declaración testimonial durante el Juicio por la Masacre de Trelew, 2012. (Archivo de audio personal)

Murphy, Jessica Priscila Tiempos de movilización, radicalización politica y nuevas formas de militancia. Un estudio de caso: la Juventud Peronista de Rawson (1969-1972), UNLP, 2017. Tesis de Licenciatura en Sociología. Disponible en: http://www.memoria.fahce.unlp.edu.ar/tesis/te.1414/te.1414.pdf] 
Ordovás, José González, "La cuestión urbana: algunas perspectivas críticas", Revista de Estudios Políticos (nueva época), núm. 101, julio-septiembre, 1998, p., 303-333.

Pérez Álvarez, "Polos de desarrollo, acumulación originaria y expansión capitalista. Un estudio comparativo del estado argentino, brasileño y español”, Revista Theomai, núm. 34, Quilmes, 2016.

Pérez Álvarez, Gonzalo y Binder, Axel, “¿Violencia política o política violenta? Reflexiones metodológicas desde el estudio del "Trelewazo", ponencia presentada en el III Coloquio Internacional sobre Violencia Politica en el Siglo XX y IV Jornadas de Trabajo de la Red de Estudios sobre Represión y Violencia Politica (RER), Rosario, 2019.

Schvarzer Jorge, "Promoción industrial en Argentina. Características, evolución y resultados", Documentos del CISEA, núm.90, 1987.

Snow, Peter, "Desarrollo económico y seguridad nacional en el régimen militar argentino", Estudios internacionales, núm. 20, 1972, pp. 65-72.

Varesi, G., "El análisis regional en la Argentina: Enfoque teórico-metodológico y aportes para su profundización", Revista de Estudios Regionales y Mercado de Trabajo, núm. 9, 2013, pp. 25-56. Disponible en: http://www.memoria.fahce.unlp.edu.ar/art revistas/pr.6295/pr.6295.pdf

Villegas Osiris, Guillermo, Política y estrategias para el desarrollo de la seguridad nacional, Buenos Aires, Pleamar, 1969.

Zapata, A. Andamios de experiencias: Conflictividad obrera, vigilancia y represión en Argentina. Babia Blanca, 1966-1976, Facultad de Humanidades y Ciencias de la Educación, Universidad Nacional de La Plata, 2014. Tesis de posgrado. 